\title{
Parent-Child Communication about Congenital Adrenal Hyperplasia: Filipino Mothers' Experience
}

\author{
Peter James B. Abad, ${ }^{1,2}$ Mercy Y. Laurino, ${ }^{2,3}$ Sandra Daack-Hirsch, ${ }^{4}$ Lorna R. Abad ${ }^{2}$ and Carmencita D. Padilla ${ }^{2,5}$ \\ ${ }^{1}$ College of Nursing, University of the Philippines Manila \\ ${ }^{2}$ Department of Pediatrics, College of Medicine and Philippine General Hospital, University of the Philippines Manila \\ ${ }^{3}$ Institute of Public Health Genetics, University of Washington, Seattle, USA \\ ${ }^{4}$ College of Nursing, University of Iowa, USA \\ ${ }^{5}$ Institute of Human Genetics, National Institutes of Health, University of the Philippines Manila
}

\begin{abstract}
Background. Family communication facilitates coping from a genetic condition by ensuring accurate understanding of the illness, its inheritance pattern, associated recurrence risks and risk perception.
\end{abstract}

Objective. This paper explores Filipino mothers' experience in communicating information about congenital adrenal hyperplasia (CAH) to their children.

Methods. Descriptive qualitative design was used. Families affected with $\mathrm{CAH}$ were recruited via a CAH support group. Semi-structured interviews with mothers were done on the following topics: content and understanding of information communicated, reasons for communicating, and changes and adjustments in the family. Thematic analysis was used to analyze the data.

Results. Five families consisting of 11 individuals, including four mothers, were interviewed. Findings revealed that while mothers are open to communicate with their child about $\mathrm{CAH}$, this is often triggered by questions from the child. Mothers find it challenging to discuss about the condition and when they do discuss, this is most often done to facilitate better understanding among the siblings. There is an attempt to explain the inheritance of $\mathrm{CAH}$ but this is also limited to the mother's understanding.

Conclusion. The findings of the study provide guidance to health professionals on how they can support parents, particularly mothers, in discussing $\mathrm{CAH}$ with their children.

Key Words: Parent-child communication, congenital adrenal hyperplasia, genetic counseling, Philippines

Part of this paper was taken from the master's thesis in genetic counseling entitled "Communication of Genetic Information in Filipino Families Affected with Congenital Adrenal Hyperplasia" (PJ Abad, 2015).

Corresponding author: Peter James B. Abad, MSc, RN

College of Nursing

University of the Philippines Manila

Sotejo Hall, Pedro Gil St., Ermita, Manila 1000 Philippines

Telephone: +632 5231477

Email: pbabad@up.edu.ph

\section{Introduction}

The diagnosis of a genetic condition in a family poses various health, reproductive, and psychosocial consequences which affect family functioning and dynamics. Family communication facilitates coping by ensuring accurate understanding of the illness, its inheritance pattern, associated recurrence risks and risk perception. However, studies have shown that families find it challenging and have difficulty in discussing about genetic conditions. ${ }^{1-4}$ Specifically, parents are expected to discuss the illness to the family including their children but they perceive this expectation to be overwhelming and a distressing moment in family life. ${ }^{4-6}$ While it is recommended that early and ageappropriate communication be done with children, it is acknowledged that parents find it difficult to determine when, how, and what to tell to their children.7,8 Because of this difficulty and uncertainty, many parents are reserved in discussing about the genetic condition in the family ${ }^{6}$ and when they do discuss, this is usually unplanned and prompted by a major family life event. ${ }^{9}$ Children, on the other hand, have been shown to wish knowing about the genetic condition affecting the family and they prefer to learn about this gradually during childhood which would prepare them for health and reproductive considerations. ${ }^{7,9}$ There is evidence showing that withholding genetic information until children become adults affect their coping and reproductive decision-making. ${ }^{7}$ While both parents and children benefit from open and honest communication about a genetic condition, $6,7,10$ studies have also shown that both of them need professional support in the disclosure and discussion about the illness. ${ }^{9-11}$

Current studies on family communication of genetic information and parent-child communication have to date been limited to examining communication in autosomal dominant and $\mathrm{X}$-linked recessive conditions and in families from Western population. 4,7,12,13 To provide additional and culture-specific insights about how family discusses genetic condition, we undertook a qualitative study that explored family communication in Filipino families affected with congenital adrenal hyperplasia $(\mathrm{CAH})$. Briefly, $\mathrm{CAH}$ is a group of autosomal recessive disorders of the adrenal cortex 
characterized by a deficiency of cortisol biosynthesis with an excess in androgen production. ${ }^{14,15}$ Majority of cases is a result of a mutation in the CYP21 gene which causes a deficiency of the 21-hydroxylase enzyme needed in the adequate synthesis of aldosterone, cortisol, and androgens. ${ }^{15,16}$ Female individuals with the classical simple virilizing type of $\mathrm{CAH}$ often present with ambiguous genitalia while genetic males present with hyperpigmentation. ${ }^{17}$ Those with the classical salt-wasting type present with more life-threatening manifestations which include renal salt-loss, failure to thrive, poor suck and feeding, and when not treated, may lead to death. ${ }^{18}$ Individuals with the non-classical type of $\mathrm{CAH}$ have milder manifestations which include amenorrhea and anovulation for females, and short stature and oligospermia for males. ${ }^{15}$

We focused on $\mathrm{CAH}$ in this study because of the following primary reasons: a.) it is a relatively common condition in the Philippines with an incidence currently estimated at 1:14,171 livebirths; ${ }^{19}$ and b.) there is still limited literature on family communication that involved autosomal recessive conditions as most studies focused on autosomal dominant and $x$-linked conditions. ${ }^{4}$ The results of this parent study has recently been published. ${ }^{1}$ In this paper, we will report specifically on the mothers' experience in communicating genetic information to their children, both affected and unaffected by CAH.

\section{Methods}

This current study was part of a qualitative study that explored how families affected with $\mathrm{CAH}$ communicate information about the condition. ${ }^{1}$ We used descriptive qualitative design to explore on the perspective of mothers in communicating genetic information about $\mathrm{CAH}$ with their children. The parent study was given ethical clearance by the Ethics Review Board of the University of the Philippines Manila (UPMREB 2014-038-01).

Detailed description of the methods is reported in detail elsewhere. ${ }^{1}$ Briefly, semi-structured interviews were conducted with Filipino families with a child diagnosed with $\mathrm{CAH}$ and who met the following inclusion criteria: a.) have a child diagnosed with CAH (whether classical or nonclassical); b.) the CAH diagnosis had been known to the family for at least five months since this time delay is assumed to give enough time for family members to communicate; c.) the family has access to peer support group or a health professional who can address any psychosocial issues that may arise following the interview. The families were recruited from $\mathrm{CAH}$ sa Pilipinas (CAHSAPI), a $\mathrm{CAH}$ family support group based in Metro Manila, Philippines. Recruitment letters were given to all members of the support group through email and their social media account. Families who signified interest to participate were contacted and interview was set after informed consent had been given. The interview schedule was developed based on literature review and contained open-ended questions on the following topics: content and understanding of information communicated, reasons and barriers in sharing information, and changes and adjustments in the family after learning about the condition.

Thematic analysis as described by Braun and Clarke ${ }^{20}$ and Smith et $\mathrm{al}^{21}$ was used to analyze the data. Because the data set was relatively small, coding, categorizing and sorting were done using a word processing software. While transcripts were read repeatedly, initial ideas that answered the research questions were annotated and coded. The data set was independently coded by two of the authors (PJBA and MYL) and reviewed by the other authors. Codes were compared for similarities and differences. Codes that related to each other were then grouped together and assigned to a thematic category. All of the authors discussed any disputes in the codes or thematic categories generated until consensus was reached. The entire process was done iteratively and proceeded as long as new codes and descriptive categories continued to emerge.

\section{Results}

We interviewed five families consisting of 11 individuals in the parent study. In this paper, we report the findings from interviews with the four mothers included as study participants. In one family, the mother was not interviewed because she declined to participate. For ethical reasons, her reason for not participating was not explored further. All of the informants are based in Manila, the capital city and all are members of CAHSAPI. Table 1 presents the demographic characteristics of the five families with information about the four mothers highlighted.

The findings are reported based on the following thematic categories: role and motivation in communicating; initiating discussion; content and strategy in communicating; and impact to children. Exemplar quotes are provided to illustrate the thematic categories.

\section{Role and Motivation in Communicating}

The mother is usually the parent who discusses and explains the condition to the child. Mothers saw the need to talk to their affected child about his/her condition primarily to prepare the child for repeated and routine procedures like blood extractions. In this sense, the mothers were attempting to manage the child's behavior rather than to give information about CAH. Jes, a mother of an 8-year-old child with CAH narrated: I now explain to him because there are things he needs to undergo... Now he is behaved whenever blood is being drawn unlike before when is shouting and crying.

Mothers' conversations with their unaffected children consisted of explaining CAH so they would understand the situation of their affected sibling. This was done usually to prevent any conflict and possible sibling rivalry that may arise as a result of more attention given to the affected child. 
Table 1. Key demographic characteristics of the informants

\begin{tabular}{|c|c|c|c|c|c|c|c|c|}
\hline Family & Participant (code name) & Age (in yrs.) & Sex & Educational Attainment & Civil Status & Religion & Relationship to Proband & Birth Order of Proband \\
\hline 1 & Ana & 57 & $\mathrm{~F}$ & HS & Married & RC & Paternal Grandmother & Only child \\
\hline \multirow{4}{*}{2} & Bea & 20 & $\mathrm{~F}$ & Presently in college & Single & $\mathrm{RC}$ & Mother & Only child \\
\hline & Luz & 45 & $\mathrm{~F}$ & College & Married & $\mathrm{RC}$ & Maternal Grandmother & \\
\hline & Rina & 18 & $\mathrm{~F}$ & Presently in College & Single & $\mathrm{RC}$ & Maternal Aunt & \\
\hline & Lar & 55 & $\mathrm{~F}$ & HS & Married & $\mathrm{RC}$ & Grand aunt & \\
\hline \multirow[t]{2}{*}{3} & Jes & 42 & $\mathrm{~F}$ & HS & Married & $\mathrm{RC}$ & Mother & Youngest \\
\hline & Lenny & 62 & $\mathrm{~F}$ & Elementary & Widow & $\mathrm{RC}$ & Maternal Grandmother & \\
\hline \multirow[t]{3}{*}{4} & Jen & 36 & $\mathrm{~F}$ & College & Married & $\mathrm{RC}$ & Mother & Eldest and youngest \\
\hline & Sam & 18 & M & Currently in high school & Single & Christian & One of the probands & \\
\hline & Maria & 57 & $\mathrm{~F}$ & HS & Married & $\mathrm{RC}$ & Paternal Grandmother & \\
\hline 5 & Josie & 35 & $\mathrm{~F}$ & College & Married & INC & Mother & Youngest \\
\hline
\end{tabular}

Note: mother participants are highlighted in the table

Abbreviations: Sex- (M-male; F-female); Educational Attainment- (HS- high school); Religion- (RC- Roman Catholic; INC- Iglesia ni Cristo)

Source: Parent study ${ }^{1}$

One of the informants, Jen, narrated how she talked to her unaffected child whenever her two sons fight: Sometimes, when they fight each other, I tell [my older son] to be understanding with his younger brother. I tell him that his brother is sick while he is normal. In other words, you are not sick so you should be the one to understand your brother.

Mothers also see the need to communicate to their child about the condition because they see it as a family affair and the unaffected children have the right to know about the condition. Josie, one of the informants narrated: It is a concern of the family so my children needs to know so that they will be aware.

\section{Initiating Discussion}

Questions from children can trigger communication between parent and child. An informant reported that her unaffected children, aged 11-14 years old, commonly asked about what happened to their affected sibling and how did the condition came about. They also asked whether they will have the same condition. Josie narrated: My eldest, when he saw his brother getting hospitalized, asked me "Mommy, what's that? Where do we get it? Do we have something like that also?"

On the other hand, the questions of the affected child were more directed towards the observable changes in his/her body. One mother narrated how her affected child asked her questions about his body when he graduated from elementary school and at the time that he was starting to be attracted with the opposite sex. Jen said: He said "Mama, why do I have a penis that appears differently from other boys?" He is always asking, "why is it like this Mama?"

\section{Content and Strategy in Communicating}

Mothers started explaining about $\mathrm{CAH}$ when their children, both affected and unaffected, entered grade school and when the children, upon the judgment of the parents, are capable of understanding simple concepts. Mothers found it challenging to explain the condition to their children especially the information about inheritance and genetics. They attempted to explain inheritance by using analogy that the child can understand and by relating it to the child's previous experience or knowledge. For example, in one family where the elder unaffected sibling was actively asking about how his brother got the condition, the mother explained by using familiar objects like cartoon characters and used it as an analogy to illustrate how inheritance occurred. She also related it to the science topics the child learned in school. The mother, Josie, narrated her conversation with her child: I said to my son "the doctor said, it is the same for both your dad and I we have something inside but ours were inactive. In [your brother] it is active. Then, he responds with a joke "Mommy that is cool, like Voltes V. a it's like Voltes V". He also said "I know that mommy, the chromosome, the $X$ " because he knows that from his science subject. Mothers did not discuss about recurrence risks to their children because the mothers themselves have limited understanding of recurrence and reproductive risks.

Mothers were protective of their affected child and this influenced how they discussed the condition with their unaffected children. For example, one mother told her elder son about his younger brother being sick but did not elaborate more on $\mathrm{CAH}$ because the former may not understand well. The mothers' approach the disclosure by explaining why and how to take care of their affected sibling. One mother, Jen, reported saying this to her unaffected child: Your brother is sick. He needs you to be kind. Don't make him cry or swear because he will have salt imbalance.

Mothers encouraged and guided their children to look for more information about $\mathrm{CAH}$ in the internet to facilitate understanding of the condition. To illustrate, the mother of a proband with ambiguous genitalia used the internet to show her son examples of individuals with the same condition and manifestations so the child can understand his situation better. Jen, the mother said: I said, "Son, you do want to see someone like you in the internet? Pictures of people with the same condition as you have?" Then he learned to search what his disease

${ }^{a}$ Voltes $\mathrm{V}$ is a Japanese anime series being shown in local television in the Philippines. 
is because he saw it on the internet, the appearance of his genitals he saw in the picture, the ambiguous. "Ah, mama, this is like mine", so he is not afraid that maybe he's an alien, that he's different, that there are other people who has that, that it needs to be treated, that it needs to be operated on.

\section{Impact to Children}

The diagnosis can either foster the closeness of siblings or can be a barrier to sibling relationship. After learning that their brother is sick and needs more attention from their mother, the elder unaffected siblings in one family expressed their desire to help in taking care of their younger brother and often asked their mother how they can be of help. The eldest sibling in this family even shared his desire to finish his education as soon as possible so he can help in the sustenance of his brother's medicines and other needs. In another family, however, the mother reported having a difficult relationship between the middle child and the two probands where the former felt apathetic about his siblings' condition and turns away every time the family discusses about CAH. She also stated that the two probands get along well together probably because of the special bond they have being both affected with CAH. Jen, the mother said: It is usually just the two brothers who bond together, the other one does not bond with them really well.

\section{Discussion}

The findings of this study suggest that parents share information about $\mathrm{CAH}$ with both their affected and unaffected children. Mothers are the primary caregivers in these families and as such they take on the role of primary communicator to their children. The information that mothers share and their motivation in sharing information depends on whether they are sharing it with their affected or unaffected child. Mothers were motivated to explain and discuss the condition to their affected children to elicit cooperation especially in laboratory procedures like blood extractions. They also shared information about $\mathrm{CAH}$ because it was an opportunity to explain the developmental changes that is happening with the affected child. On the other hand, mothers shared information to their unaffected children to foster good emotional relationships among siblings. They proactively communicated with their children about the CAH diagnosis and this contributed to unaffected children having deeper understanding and sympathy on their affected sibling's condition. This finding highlights the need for both affected and unaffected children to be involved in the discussion about the condition so they have better understanding of their roles and expectations in the family. This is consistent with other studies suggesting that parents disclose information to their children because of the belief that knowing about the information will strengthen relationships ${ }^{9,22}$ and foster emotional wellbeing and adjustment in the family. ${ }^{6}$
Information about $\mathrm{CAH}$ was shared to the children but this was also often preceded by a question coming from the child. The level and type of questions the children ask were dependent on their developmental stage, current life circumstances and their observation of their affected sibling. The findings suggest that both affected and unaffected children start to ask questions at around 11-14 years old when the children are gaining more understanding about the condition based on what they observe and how it affects daily living. ${ }^{6}$ Studies have shown that children ask questions about the condition because of their desire to know and be informed. ${ }^{5,6,9}$ It could be an indication of the child's readiness to receive information and when this happens, parents take advantage of the opportunity to initiate conversations about the condition. ${ }^{23}$ In answering the questions, parents give information that is tailored to the child's developmental level. ${ }^{11}$ They may also use reframing strategies in communicating information with children to downplay the illness or its management, and to focus on the state of normalcy to prevent further negative emotional outcomes. ${ }^{23}$ In this study, parents used age-appropriate language and techniques such as analogy to explain the condition to the child, and non-threatening words relating it to previous experience, say a lesson discussed in class. The process of informing children is not necessarily accomplished in a single conversation, but can unfold throughout childhood.

Previous studies have found 'critical stage' throughout the lifespan by which parents are inclined to disclose genetic information to their children. These critical stages include birth, first sexual experience, and marriage. ${ }^{7}$ In this study, it was found that adolescence may also be a critical stage since in this stage, the child faces physiologic changes as primary and secondary sex characteristics are starting to emerge. ${ }^{24}$ In this same period, the child encounters developmental crisis in forming his/her own identity. ${ }^{25,26}$ Due to the possibility of ambiguous genitalia and the issues and difficulties encountered in gender assignment, ${ }^{27}$ adolescence is a particularly important stage for the child because of the various milestones, and physical and psychosocial concerns on this stage as mentioned above. As such, parents may need to give special attention especially for their children approaching adolescence and to expect that more questions will be asked which the parents need to prepare for.

The information communicated by mothers with their children is focused on the management and support needs of the affected child and not on the reproductive implications of the condition to the children. This can be attributed to the mothers' judgement that the children were not developmentally ready to receive such information and to the mothers' limited understanding of the reproductive implications of CAH. Previous studies that examined parent child communication ${ }^{6,9}$ also highlighted limited understanding of genetic information as an important factor that determines the extent of genetic information shared. 
Gallo et $\mathrm{al}^{28}$ referred to this information management pattern as the confused understanding pattern in which parents are confused in one or two genetic concepts including the likelihood of others in the family including their offspring to be carriers, and the likelihood of passing on the mutated gene to their offspring. This finding highlights the need for parents to be given accurate health and genetic information about the condition to assist them to convey this same information to others including their children. Moreover, having a good understanding of these concepts may enable parents to address questions especially that their children are approaching reproductive age. Genetic counselors, pediatric endocrinologists, and other health professionals such as nurses can support parents, particularly mothers, by providing accurate information about CAH. Recurrence risks are particularly important information that needs to be discussed with the parents. Health care professionals working with these families need to walk the parents through the possible scenarios in discussing concepts about inheritance and risks with their children. Follow-up consultation visits are crucial to ensure that appropriate and accurate information are understood by parents. This is also important so that parents are guided on the right information especially those found online and other resources.

This study provides guidance for health care professionals in supporting the communication of parents with their children about a genetic condition that affects the family. A primary strength of this paper is that it involves parents of Filipino descent and this provides an insight on how parent-child communication happens in this cultural group. However, the findings of this study need to be considered in light of its limitations. This is a small study that included only four mothers as study participants. The findings, therefore, may not be applicable to mothers and families who did not participate in the study. Since recruitment was through the parent support group, it may also be possible that those who agreed to participate are those who have already coped and adapted to the condition. Their experiences in communicating may thus be different from those who are not members of the support group. The findings may not be applicable to the other ethnolinguistic groups in the Philippines as the study participants were recruited within the capital city and it may not represent the communication patterns in the rest of the country considering that there are 175 ethnolinguistic groups in the Philippines.

To understand better how parents and children communicate about $\mathrm{CAH}$ and to exhaust all possible thematic categories in this research area, future studies may want to include more parents as study participants. The insights and perspectives of the children, both affected and unaffected, themselves may complete the picture of the communication patterns, and hence they could also be included in future studies.

\section{Summary}

In summary, while mothers are open to communicate with their children about $\mathrm{CAH}$, this is often triggered by questions from the children. Mothers find it challenging to discuss about the condition and when they do discuss, this is most often done to facilitate better understanding among the siblings. There is an attempt to explain the inheritance of $\mathrm{CAH}$ but this is also limited to how mothers understood the concept. The role of genetic counselors and pediatric endocrinologists as well as other health care professionals dealing with families affected with $\mathrm{CAH}$ is crucial to ensure that accurate information about the condition is disseminated and support to these families as they cope with the condition is provided.

\section{Acknowledgments \\ The authors thank the families and the mothers who participated in the study. Their stories have inspired us to improve genetic counseling service provision to families affected with CAH. Ms. Leoant Santos, RN provided valuable administrative assistance in the conduct of the study. Aprille Banayat, RN critically read and edited the paper.}

\section{Statement of Authorship}

All authors have approved the final version submitted.

\section{Author Disclosure}

All authors declared no conflict of interest.

\section{Funding Source}

The parent study is funded by the UP Manila NIH-Newborn Screening Reference Center.

\section{References}

1. Abad PJB, Anonuevo CA, Daack-hirsch S, Abad LR, Padilla CD, Laurino MY. Communication about Congenital Adrenal Hyperplasia: Perspective of Filipino Families. J Genet Couns. 2017; 26(4):763-75. doi:10.1007/s10897-016-0043-x.

2. Nycum G, Avard D, Knoppers BM. Factors influencing intrafamilial communication of hereditary breast and ovarian cancer genetic information. Eur J Hum Genet. 2009; 17(7):872-80. doi:10.1038/ ejhg.2009.33.

3. Tercyak KP, Hughes C, Main D, et al. Parental communication of BRCA1/2 genetic test results to children. Patient Educ Couns. 2001; 42(3):213-24. doi:10.1016/S0738-3991(00)00122-1.

4. Gaff CL, Clarke AJ, Atkinson P, et al. Process and outcome in communication of genetic information within families: a systematic review. Eur J Hum Genet. 2007; 15(10):999-1011. doi:10.1038/ sj.ejhg. 5201883 .

5. Metcalfe A, Coad J, Plumridge GM, Gill P, Farndon P. Family communication between children and their parents about inherited genetic conditions: a meta-synthesis of the research. Eur J Hum Genet. 2008; 16(10):1193-200. doi:10.1038/ejhg.2008.84. 
6. Metcalfe A, Plumridge G, Coad J, Shanks A, Gill P. Parents' and children's communication about genetic risk: a qualitative study, learning from families' experiences. Eur J Hum Genet. 2011; 19(6):640-6. doi:10.1038/ejhg.2010.258.

7. Rowland E, Metcalfe A. Communicating inherited genetic risk between parent and child: A meta-thematic synthesis. Int J Nurs Stud. 2013; 50(6):870-80. doi:10.1016/j.ijnurstu.2012.09.002.

8. McConkie-Rosell A, Del Giorno J, Heise EM. Communication of genetic risk information to daughters in families with fragile $X$ syndrome: The parent's perspective. J Genet Couns. 2011; 20(1):58-69. doi:10.1007/ s10897-010-9326-9.

9. Plumridge G, Metcalfe A, Coad J, Gill P. Parents' communication with siblings of children affected by an inherited genetic condition. J Genet Couns. 2011; 20(4):374-83. doi:10.1007/s10897-011-9361-1.

10. Pentz RD, Peterson SK, Watts B, et al. Hereditary nonpolyposis colorectal cancer family members' perceptions about the duty to inform and health professionals' role in disseminating genetic information. Genet Test. 2005; 9(3):261-8. doi:10.1089/gte.2005.9.261.

11. Aktan-Collan KI, Kääriäinen HA, Kolttola EM, et al. Sharing genetic risk with next generation: Mutation-positive parents' communication with their offspring in Lynch Syndrome. Fam Cancer. 2011; 10(1):43-50. doi:10.1007/s10689-010-9386-x.

12. Wilson BJ, Forrest K, van Teijlingen ER, et al. Family communication about genetic risk: the little that is known. Community Genet. 2004; 7(1):15-24. doi:10.1159/000080300.

13. Hay J, Dibonaventura M, Baser R, Press N, Shoveller J, Bowen D. Personal attributions for melanoma risk in melanoma-affected patients and family members. J Behav Med. 2011; 34(1):53-63. doi:10.1007/s10865010-9286-4.

14. Hughes IA. Congenital adrenal hyperplasia--a continuum of disorders. Lancet. 1998; 352(9130):752-4. doi:10.1016/S0140-6736(98)22037-X.

15. Merke DP, Bornstein SR. Congenital adrenal hyperplasia. Lancet. 2005; 365(9477):2125-36. doi:10.1016/S0140-6736(05)66736-0.

16. Collett-Solberg PF. Congenital adrenal hyperplasia: from genetics and biochemistry to clinical practice, part 2. Clin Pediatr (Phila). 2001; 40(3):125-32. doi:10.1177/000992280104000301.

17. Bonfig W, Schmidt H, Schwarz HP. Growth patterns in the first three years of life in children with classical congenital adrenal hyperplasia diagnosed by newborn screening and treated with low doses of hydrocortisone. Horm Res Pædiatr. 2011;75(1):32-7. doi:10.1159/000316973.

18. Janjanin N, Dumic M, Skrabic V, Kusec V, Grubic Z, Spehar Uroic A. Five patients with congenital adrenal hyperplasia due to 21-hydroxylase deficiency (one with associated neuroblastoma) discovered in three generations of one family. Horm Res. 2007; 67(3):111-6. doi:10.1159/ 000096420.

19. Newborn Screening Reference Center. Prevalence of Disorders Among Filipino Newborns (1996-2014) [Online]. 2014 [cited 2015 May]. Available from http://www.newbornscreening.ph/images/stories/ ResourcesPrevalence/prevalence-2014.pdf.

20. Braun V, Clarke V. Using thematic analysis in psychology. Qual Res Psychol. 2006; 3(2):77-101.

21. Smith JA, Dancyger C, Wallace M, Jacobs C, Michie S. The development of a methodology for examining the process of family communication of genetic test results. J Genet Couns. 2011; 20(1):23-34. doi:10.1007/s10897 010-9317-x.

22. McConkie-Rosell A, Heise EM, Spiridigliozzi GA. Genetic risk communication: experiences of adolescent girls and young women from families with Fragile X Syndrome. J Genet Couns. 2009; 18(4):313-25.

23. Gallo AM, Angst D, Knafl KA, Hadley E, Smith C. Parents sharing information with their children about genetic conditions. J Pediatr Health Care. 2005;19(5):267-75. doi:10.1016/j.pedhc.2005.05.008.

24. Boyd DR, Bee HL, Johnson PA. Lifespan Development. Pearson/A and B; 2006.

25. Rosenthal DA, Gurney RM, Moore SM. From trust on intimacy: A new inventory for examining Erikson's stages of psychosocial development. J Youth Adolesc. 1981; 10(6):525-37.

26. Zimmer-Gembeck MJ, Collins WA. Autonomy Development during Adolescence. Oxford: Blackwell Publishers; 2003.

27. Meyer-Bahlburg HF, Dolezal C, Baker SW, Ehrhardt AA, New MI Gender development in women with congenital adrenal hyperplasia as a function of disorder severity. Arch Sex Behav. 2006; 35(6):667-84 doi:10.1007/s10508-006-9068-9.

28. Gallo AM, Knafl KA, Angst DB. Information management in families who have a child with a genetic condition. J Pediatr Nurs. 2009; 24(3):194-204. doi:10.1016/j.pedn.2008.07.010. 